\title{
Research Organization Effective Date Range
}

National Cancer Institute

\section{Source}

National Cancer Institute. Research Organization Effective Date Range. NCI Thesaurus.

Code C94060.

The date and time span for when the research organization is active. 